\title{
Corrosion Behaviour of a New Low-Nickel Stainless Steel Reinforcement: A Study in Simulated Pore Solutions and in Fly Ash Mortars
}

\author{
M. Criado, ${ }^{1}$ S. Fajardo, ${ }^{2}$ and J. M. Bastidas $^{2}$ \\ ${ }^{1}$ Materials Science Institute of Madrid (CSIC), Energy, Environmental, and Sustainable Technologies, \\ Sor Juana Inés de la Cruz 3, 28049 Cantoblanco-Madrid, Spain \\ ${ }^{2}$ National Centre for Metallurgical Research (CENIM), CSIC, Surface Engineering, Corrosion, and Durability, \\ Avenida Gregorio del Amo 8, 28040 Madrid, Spain
}

Correspondence should be addressed to M. Criado, mcriado@icmm.csic.es

Received 23 December 2011; Accepted 24 February 2012

Academic Editor: Citlalli Gaona Tiburcio

Copyright ( $) 2012$ M. Criado et al. This is an open access article distributed under the Creative Commons Attribution License, which permits unrestricted use, distribution, and reproduction in any medium, provided the original work is properly cited.

\begin{abstract}
The present paper studies the corrosion behaviour of a new lower-cost type of austenitic stainless steel (SS) with a low nickel content in alkaline-saturated calcium hydroxide solution (a simulated concrete pore (SCP) solution) with sodium chloride $(0.0 \%$, $0.4 \%, 1.0 \%, 2.0 \%, 3.0 \%$, and $5.0 \% \mathrm{NaCl}$ ) and embedded in alkali-activated fly ash (AAFA) mortars manufactured using two alkaline solutions, with and without chloride additions (2\% and 5\%), in an environment of constant $95 \%$ relative humidity. Measurements were performed at early age curing up to 180 days of experimentation. The evolution with time of electrochemical impedance spectroscopy was studied. $R_{\mathrm{ct}}$ values obtained in SCP solution or in fly ash mortars were so high that low-nickel SS preserved its passivity, exhibiting high corrosion resistance
\end{abstract}

\section{Introduction}

Steel reinforcements embedded in concrete are protected from corrosion by a thin oxide film formed on their surfaces and maintained by the highly alkaline environment of the surrounding concrete, usually with a $\mathrm{pH}$ of 12-13 [1]. However, the presence of chlorides can lead to damaging effects on passivity and the appearance of pitting corrosion when chloride ions reach the metal/concrete interface. Chloride ions are commonly found in construction materials and may originate from the external environment, as in the case of marine environments, deicing salts and acid rain [2]. While thermodynamic can predict whether a corrosion reaction will take place, it does not provide an indication of the rate of corrosion reactions. The reaction kinetics depends on the determinant factors such as humidity, oxygen, and alkalinity medium. These factors can speed up the corrosion process $[3,4]$.

Together with cathodic protection and corrosion inhibitors, stainless steel (SS) reinforcements are a reliable way to guarantee the durability of reinforced concrete structures (RCSs) in extremely aggressive environments $[5,6]$. Although SS reinforcements may be the most economical solution on the long term $[7,8]$, the initial cost involved has so far limited their use. For this reason, new SSs, in which the nickel content (subject to considerable price fluctuations due to stock market factors) is partly replaced by other elements [ 9 , 10], are being evaluated as possible alternatives to traditional carbon steel $[11,12]$. This new low-nickel SS could mean a saving of about $15-20 \%$ compared to conventional AISI 304 SS.

Low-nickel austenitic SSs exhibit attractive properties that are comparable to those of traditional austenitic SSs, such as good corrosion resistance, high levels of strength and ductility, and reduced tendency of grain sensitization [13]. Previous researches $[14,15]$ have shown that the carbon steel corrosion rate values are similar to those of the traditional and low-nickel austenitic SSs in mortar without chloride additions, and at least 10 times higher in the presence of chloride. Furthermore, low-nickel austenitic SSs have had 
a corrosion behaviour very similar to that of traditional austenitic SSs in carbonated media and noncarbonated, chloride-contaminated media [16].

The aim of this paper is to study the corrosion behaviour of a new type of austenitic SS, with a low-nickel content, in alkaline-saturated calcium hydroxide solution (a simulated concrete pore (SCP) solution) with sodium chloride $(\mathrm{NaCl})$ and embedded in alkali-activated fly ash mortar with different chloride additions. Fly ash is used in concrete for reasons related to environmental impact, economic sustainability, and social responsibility. The alkali activation of type $\mathrm{F}$ fly ash (AAFA) consists of mixing the ash with highly alkaline solutions $(\mathrm{pH}>13)$ and subsequently curing the resulting paste at a certain temperature to produce a solid material. Considering that reinforcement corrosion is the main cause of RCS failure [17], the capacity of an AAFA mortar to passivate steel rebars is a very important property to guarantee the durability of RCS constructed using these new materials.

\section{Experimental}

The test specimens carried out in alkaline-saturated calcium hydroxide solution (a SCP solution) consisted of $5.0 \mathrm{~cm} \times$ $2.0 \mathrm{~cm}$ size and $1 \mathrm{~mm}$ thickness of plates of low-nickel austenitic SS. The specimens were ground using a series of silicon carbide ( $\mathrm{SiC}$ ) emery papers down to grade 600, and then ultrasonically cleaned with ethanol and rinsed with highpurity water. The decision to use plates instead of traditional bars was due to the design of the electrochemical cell. An Avesta type cell was used, which allows crevice corrosion to be avoided or minimised [18] by replacing the chloride solution in the microcrevice between the specimen and the specimen holder with small quantities of distilled water.

The low-nickel SS samples were supplied by ACERINOX SA (Palmones, Cádiz, Spain), this type of SS is an AISI 201 [19] or EN 1.4372 [20]. Table 1 shows the chemical composition of the plates of SS.

A saturated calcium hydroxide solution, $\mathrm{pH} \sim 12-13$, with different $\mathrm{NaCl}$ concentrations $(0.0,0.4,1.0,2.0,3.0$, and $5.0 \mathrm{wt} . \%)$, was used to study corrosion behaviour in a wide range of experimental conditions. The chemical products used to prepare the solutions were laboratory grade reagents: $\mathrm{NaCl}$ 99\% pure PRS-CODEX supplied by Panreac and $\mathrm{Ca}(\mathrm{OH})_{2}$ for analysis supplied by Merck. All the solutions were prepared with distilled water.

The Avesta cell was used in a three-electrode configuration with the sample as the working electrode, a saturated calomel electrode (SCE) as reference, and a platinum mesh as counter electrode, see Figure 1. All the potentials were thus referred to the SCE.

On the other hand, class F fly ash from the thermal power plant at Aboño in Asturias, Spain, was used. Table 2 indicates its chemical composition. The fly ash was activated with two different highly alkaline solutions. Two types of AAFA mortars were manufactured: one with a $\mathrm{NaOH}$ solution (A specimen) and the other with a mixture of $85 \% \mathrm{NaOH}$ and $15 \%$ waterglass (B specimen) with a "liquid/solid" ratio of 0.45 . The aggregate/AAFA ratio used to manufacture the mortars

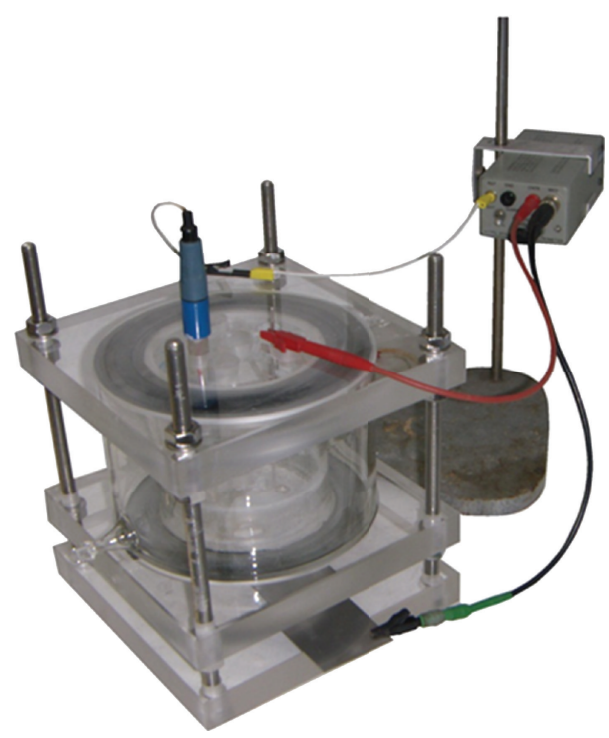

Figure 1: An Avesta type cell and the assembly used in the electrochemical tests.

TABLE 1: Chemical composition (\% by weight ${ }^{\mathrm{a}}$ ) of the tested austenitic low-nickel SS.

\begin{tabular}{cccccccccc}
\hline $\mathrm{C}$ & $\mathrm{Si}$ & $\mathrm{Mn}$ & $\mathrm{P}$ & $\mathrm{S}$ & $\mathrm{Cr}$ & $\mathrm{Ni}$ & $\mathrm{Mo}$ & $\mathrm{Cu}$ & $\mathrm{N}$ \\
\hline 0.082 & 0.48 & 7.26 & 0.027 & 0.001 & 16.56 & 4.32 & 0.07 & 0.13 & 0.075 \\
\hline
\end{tabular}

${ }^{\mathrm{a}}$ The balance was Fe.

was 2. A standardised, evenly graded siliceous sand was employed $\mathrm{SiO}_{2}$ content of $99 \%$, where $66 \%$ of particles with size $<1 \mathrm{~mm}$ and $35 \%<0.5 \mathrm{~mm}$ ). The moulds containing the fresh AAFA mortars were subsequently cured in an oven at $85^{\circ} \mathrm{C}$ in a saturated water vapour atmosphere for $20 \mathrm{~h}$. Different amounts of sodium chloride (99\% pure Panreac PRS-CODEX): $0,2 \%$, and $5 \% \mathrm{NaCl}$ (with respect to binder weight) were added to fly ash. Two mortar prism replicas of each type were prepared for comparative purposes. All the specimens were kept at room temperature in an atmosphere of high relative humidity $(\mathrm{RH})$ of approximately $95 \%$, for up to 180 days.

Experiments were performed on small prismatic specimens measuring $8 \times 5.5 \times 2 \mathrm{~cm}$, similar to those used in previous works $[3,4]$. Two $10 \mathrm{~mm}$ diameter, low-nickel SS rebar, symmetrically embedded in the prisms, were used as working electrodes during the measurements, with an external SS cylinder of $5 \mathrm{~cm}$ diameter acting as a counter electrode. A pad soaked in water was used to enable the electrical conductivity measurements. An active surface area of $5.6 \mathrm{~cm}^{2}$ was marked on the working electrodes with adhesive tape, thus isolating the triple mortar/steel/atmosphere interface to avoid possible localised corrosion attack due to differential aeration. The use of the three-point measurement can generate some measurement perturbations like capacitive or inductive loops at high frequency [21]. In this study the stainless steel cylinder electrode (the same size as the specimens) was used to confine the current lines in a specific area, achieving a uniform 


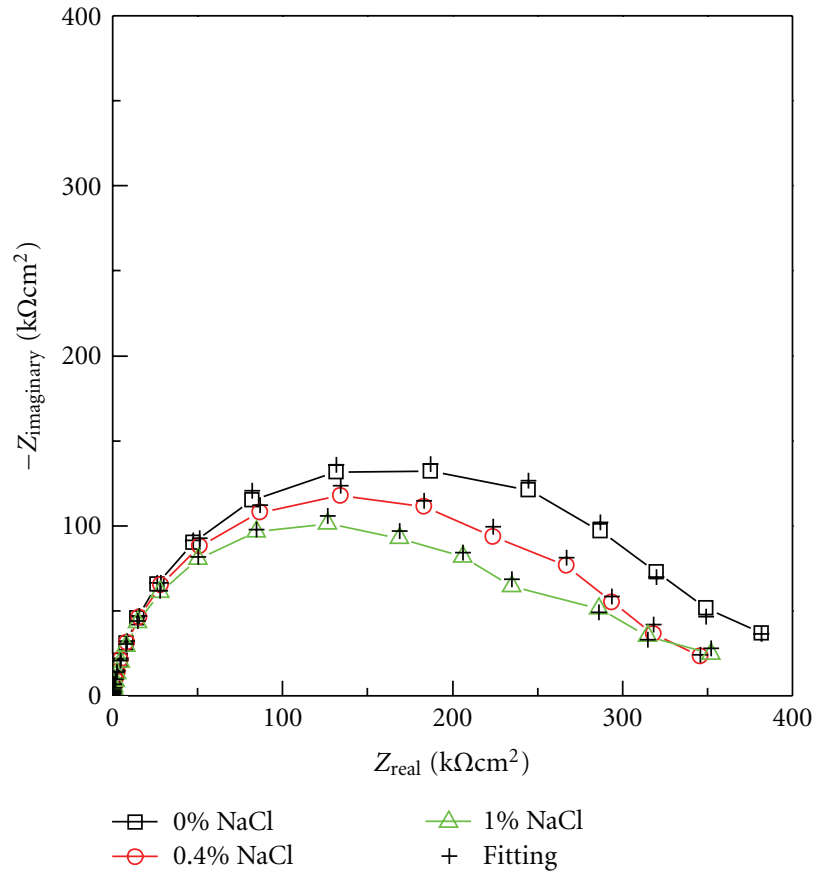

(a)

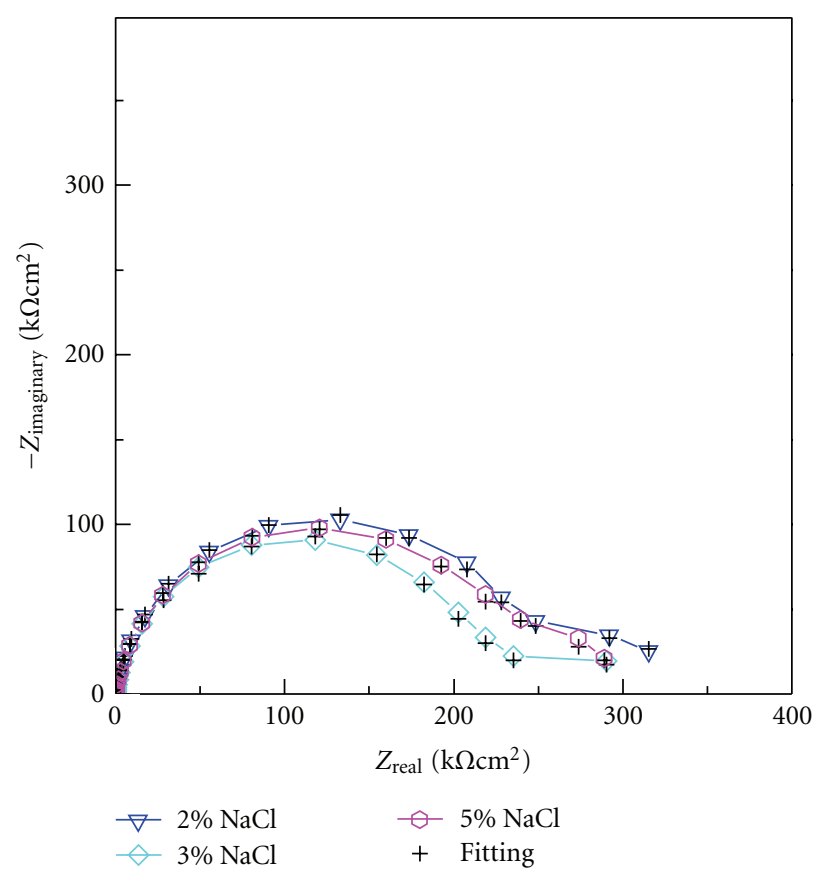

(b)

FIGURE 2: Nyquist plots for low-nickel SS in $\mathrm{Ca}(\mathrm{OH})_{2}$-saturated solution with different $\mathrm{NaCl}$ concentrations: (a) $0.0,0.4,1.0 \%$, and (b) 2.0 , $3.0,5.0 \%$.

TABLE 2: Chemical composition of the tested fly ash (\% in mass).

\begin{tabular}{cccccccccccccc}
\hline $\mathrm{SiO}_{2}$ & $\mathrm{Al}_{2} \mathrm{O}_{3}$ & $\mathrm{Fe}_{2} \mathrm{O}_{3}$ & $\mathrm{CaO}$ & $\mathrm{MgO}$ & $\mathrm{SO}_{3}$ & $\mathrm{Na}_{2} \mathrm{O}$ & $\mathrm{K}_{2} \mathrm{O}$ & $\mathrm{MnO}$ & $\mathrm{P}_{2} \mathrm{O}_{5}$ & $\mathrm{TiO}_{2}$ & LOI & Others & Total \\
\hline 51.78 & 27.80 & 6.18 & 4.59 & 1.52 & 0.71 & 0.59 & 2.51 & 0.06 & 0.62 & 1.35 & 2.23 & 0.06 & 100 \\
\hline
\end{tabular}

LOI: Loss on ignition.

distribution of the current lines and therefore the measurements not suffer perturbations.

Electrochemical impedance spectroscopy (EIS) measurements were recorded at $\mathrm{E}_{\text {corr }}$ in a frequencies range from $10^{5} \mathrm{~Hz}$ to $10^{-3} \mathrm{~Hz}$ with a logarithmic sweeping frequency of 5 points per decade. The EIS method involved the imposition of a $10 \mathrm{mV}$ rms amplitude excitation voltage. A 1250 Solartron Frequency Response Analyser linked to an EG\&G PARC 273A potentiostat was used for EIS measurements.

\section{Results and Discussion}

Figure 2 shows Nyquist plots for low-nickel SS in $\mathrm{Ca}(\mathrm{OH})_{2}$ saturated solution with different $\mathrm{NaCl}$ concentrations. Capacitive behaviour can be observed, characterized by a well-defined depressed semicircle. The depressed semicircle was generally due to dispersion of the time constant caused by irregularities on the steel surface, surface roughness, fractal surface, and, in general, certain processes associated with an irregular distribution of the applied potential [22]. Diffusion processes were defined at low frequencies.

Impedance data has been modelled using the equivalent electrical circuits (EECs) depicted in Figure 3 for low-nickel SSs. The EEC of Figure 3 contains a constant phase element (CPE) to consider the relaxation time constant. $R_{e}$ is the electrolyte resistance between the reference electrode and the working electrode, and $R_{\mathrm{ct}}$ is the charge transfer resistance, which may be inversely associated with the corrosion process. A CPE unit is often used instead of an ideal capacitor to account for a nonideal capacitive response from the steel/electrolyte interface [22]. This EEC also contains a finite length Warburg diffusion element to describe mass transport processes through the diffusion layer. A one time constant EEC containing a finite length Warburg diffusion element has previously been used by other authors to describe the behaviour of SS in chloride-containing solutions [23]. Table 3 reports the fitting of impedance data for low-nickel SS in $\mathrm{Ca}(\mathrm{OH})_{2}$ saturated solution with different $\mathrm{NaCl}$ additions yielded using the EEC of Figure 3.

Table 3 shows that the $R_{e}$ value decreased as $\mathrm{NaCl}$ was added to the solution. The conductivity of a water solution is highly dependent on the concentration of dissolved salts and other chemical species that ionize in the solution. Thus, as $\mathrm{NaCl}$ was added to the $\mathrm{Ca}(\mathrm{OH})_{2}$-saturated solution its conductivity grew, leading to a lower $R_{e}$ value.

The impedance results for low-nickel SS in $\mathrm{Ca}(\mathrm{OH})_{2}$ saturated solution with different $\mathrm{NaCl}$ additions presented typical capacitive behaviour, with a semicircle at high frequencies. Nevertheless, as can be seen in Figure 2, the radii of the semicircles decreased as the $\mathrm{NaCl}$ concentration 
TABle 3: Fitting impedance data using EEC of Figure 2 for low-nickel SS in $\mathrm{Ca}(\mathrm{OH})_{2}$-saturated solution with different $\mathrm{NaCl}$ concentrations.

\begin{tabular}{lcccccc}
\hline $\mathrm{NaCl} / \%$ & $R_{e} / \Omega \mathrm{cm}^{2}$ & $R_{\mathrm{ct}} / \Omega \mathrm{cm}^{2}$ & $Y_{0} / \mathrm{Fcm}^{-2} \mathrm{~s}^{-(1-\alpha)}$ & $\mathrm{A}$ & $\sigma_{w} / \times 10^{-3} \Omega \mathrm{cm}^{2} \mathrm{~s}^{-1 / 2}$ & 1.82 \\
0.0 & 176.9 & 332140 & $1.00 \times 10^{-5}$ & 0.89 & 1.76 & 0.001 \\
0.4 & 93.8 & 324870 & $2.91 \times 10^{-5}$ & 0.91 & 1.54 & 0.0008 \\
1.0 & 62,6 & 269760 & $3.00 \times 10^{-5}$ & 0.90 & 0.88 & 0.003 \\
2.0 & 37.9 & 235550 & $3.08 \times 10^{-5}$ & 0.88 & 0.002 \\
3.0 & 29.7 & 231110 & $3.25 \times 10^{-5}$ & 0.89 & 4.32 & 0.004 \\
5.0 & 19.8 & 212280 & $3.28 \times 10^{-5}$ & & 0.006 \\
\hline
\end{tabular}

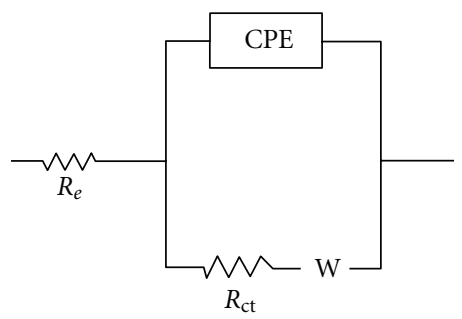

Figure 3: Equivalent electrical circuit (EEC) used to fit impedance data for low-nickel SS in a SCP solution.

increased, indicating a drop in passivity with the presence of chloride ions. The above trend can be further supported by the quantified $R_{\mathrm{ct}}$ values seen in the fitted data in Table 3.

The effect of chloride ions can also be evaluated in terms of $Y_{0}$ and $\alpha$, which are parameters of the CPE unit. CPE represents the double-layer capacitance of the steel/electrolyte interface when nonideal behaviour of the capacitor used to describe the metal/solution system is observed. As indicated above, the nonhomogeneity of the double-layer electric field and the roughness of the surface are responsible for deviation in the capacitance from the ideal condition. The impedance of a CPE $\left(Z_{\mathrm{CPE}}\right)$ is defined by the expression:, $Z_{\mathrm{CPE}}=1$ / $Y_{0}(j \omega)^{\alpha}$, where $Y_{0}$ is a real frequency-independent constant, $j^{2}=(-1), \omega$ is the angular frequency, and $\alpha$ is a dimensionless fractional exponent $(-1 \leq \alpha \leq 1)$. Therefore, the CPE-parameters $Y_{0}$ and $\alpha$ can reflect the change of a metal electrode surface relating to an electrochemical double-layer [22]. A number of studies have revealed that these parameters vary with the homogeneity of the electrode surface: higher $Y_{0}$ values and lower $\alpha$ values $(\alpha=1$ for an ideal capacitor) were characteristic of nonhomogeneous surfaces [24-26]. For low-nickel SS, $Y_{0}$ values increased with the addition of $\mathrm{NaCl}$. The variation in $Y_{0}$ values from the nonchloride-containing solution to the maximum studied $\mathrm{NaCl}$ concentration was by approximately 1-2 points in the same order of magnitude (see Table 3). This may be a sign of the loss of homogeneity on the surface of the electrode due to the effect of chloride ions. However, the small variation in $Y_{0}$ from chloride-free to the maximum tested chloride concentration suggests that low-nickel SS was able to retain its passivity in these adverse environments in unpolarized conditions. In terms of the $\alpha$ parameter, low-nickel SS showed no trend as it varied around $\sim 0.90$, exhibiting no influence of the $\mathrm{NaCl}$ concentration in the $\mathrm{Ca}(\mathrm{OH})_{2}$-saturated solution.

At low frequencies (in the $5 \times 10^{-3}-10^{-3} \mathrm{~Hz}$ range), diffusion was the controlling process for this new SS (see Figure 2). The Warburg diffusion coefficient $\left(\sigma_{w}\right)$ results from mass transport of the species through the passive layer. According to the point defect model (PDM), diffusion was allocated to the transport of vacancies through the passive film. A more stable and resistive passive film presents less defects and therefore a lower $\sigma_{w}$ due to the lower presence of vacancies available for the mass transport process. The $\sigma_{w}$ values yielded from the impedance data fitting showed that low-nickel SS exhibited similar values $(1.82-1.90 \times$ $10^{-3} \Omega \mathrm{cm}^{2} \mathrm{~s}^{-1 / 2}$ ) when the $\mathrm{NaCl}$ concentration was lower than or equal to $2.0 \%$ (see Table 3 ), which may indicate that the passive film formed at these $\mathrm{NaCl}$ concentrations presented similar corrosion stability. However, when the $\mathrm{NaCl}$ concentration is $3.0 \%$ and $5.0 \%$, an increase in the $\sigma_{w}$ values was observed. According to the PDM role, this indicates a less compact and protective passive layer.

All these results are similar to those obtained in a previous work [27] due to the experimental conditions in simulated pore solutions were identical since these conditions are normally employed to study the corrosion behaviour of the steel reinforcement.

The authors have reported in a previous research that low-nickel exhibited corrosion current density values of the order of $0.001-0.01 \mu \mathrm{A} / \mathrm{cm}^{2}$ in the presence of $0.4 \%$ and $2 \%$ chlorides, indicating the permanence of the passive state [28]. Therefore, the aim of the present work was studied the corrosion behaviour of alkali-activated fly ash mortars in more aggressive environment ( $5 \%$ chlorides), taking into account the results obtained in the simulated concrete pore solution.

Figure 4 shows typical Nyquist plots for low-nickel SS rebar embedded in mortars (a) A and (b) B with different chloride additions $(0,2 \%$, and $5 \%)$. Measurements were performed after 180 days of experimentation. In general, a capacitive behaviour was obtained, characterised by a poorly defined and depressed semicircle at high frequencies and a second semicircle at low frequencies. Tables 4 and 5 illustrate the fitting of impedance data for low-nickel SS rebar, embedded in mortar A and B, respectively. These tables were yielded using the equivalent electrical circuit (EEC) of Figure 5.

The EEC of Figure 5 contains two distributed constant phase elements $\left(\mathrm{CPE}_{\mathrm{HF}}\right.$ and $\left.\mathrm{CPE} E_{\mathrm{LF}}\right)$ to consider the two 


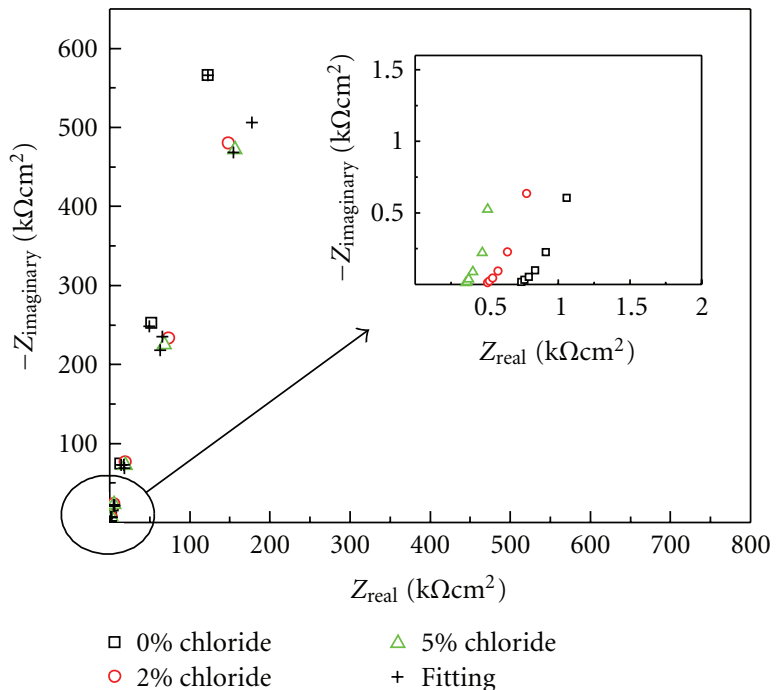

(a)

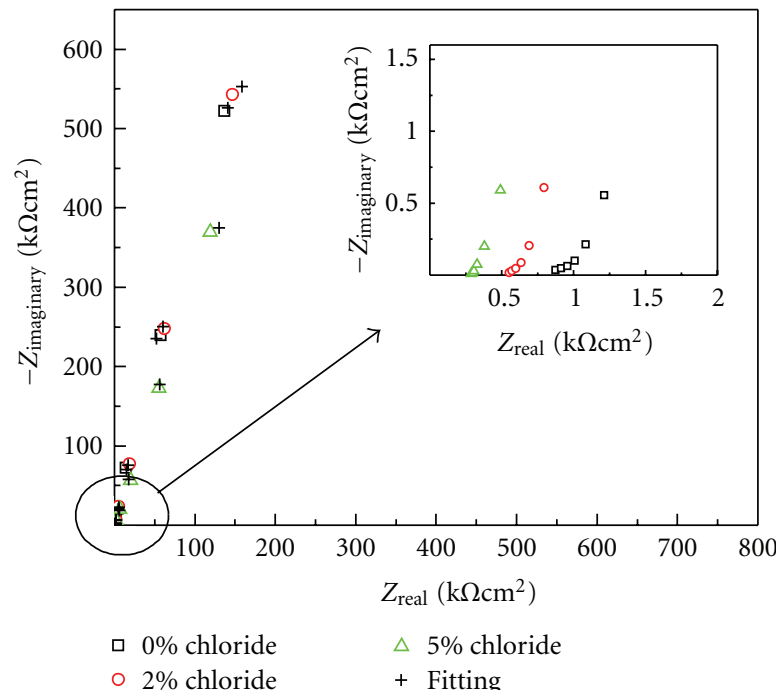

(b)

FIGURE 4: Nyquist plots for low-nickel SS for low-nickel SS rebar embedded in mortars (a) A and (b) B with different chloride additions.

TABLE 4: Parameters used in the fitting of impedance data for low-nickel SS rebar embedded in A mortar.

\begin{tabular}{|c|c|c|c|c|c|c|c|c|}
\hline Time day & $\begin{array}{c}R_{e} \\
\Omega \mathrm{cm}^{2}\end{array}$ & $\begin{array}{c}Y_{P_{\mathrm{HF}}} \\
\mu \mathrm{Fcm}^{-2} \mathrm{~s}^{-\left(1-\alpha_{\mathrm{HF}}\right)}\end{array}$ & $\alpha_{\mathrm{HF}}$ & $\begin{array}{c}R_{\mathrm{HF}} \\
\Omega \mathrm{cm}^{2}\end{array}$ & $\begin{array}{c}Y_{P_{\mathrm{LF}}} \\
\mu \mathrm{Fcm}^{-2} \mathrm{~s}^{-\left(1-\alpha_{\mathrm{LF}}\right)}\end{array}$ & $\alpha_{\mathrm{LF}}$ & $\begin{array}{c}R_{\mathrm{ct}} \\
\mathrm{k} \Omega \mathrm{cm}^{2}\end{array}$ & $\chi^{2}$ \\
\hline \multicolumn{9}{|c|}{$0 \%$ chloride } \\
\hline 1 & 1456 & 8 & 0.60 & 369 & 21 & 0.87 & 4990 & 0.001 \\
\hline 7 & 1738 & 4 & 0.65 & 407 & 21 & 0.86 & 4676 & 0.002 \\
\hline 15 & 1764 & 3 & 0.67 & 394 & 21 & 0.86 & 6933 & 0.002 \\
\hline 30 & 2078 & 4 & 0.67 & 422 & 20 & 0.86 & 13306 & 0.002 \\
\hline 60 & 2442 & 4 & 0.66 & 366 & 19 & 0.87 & 9307 & 0.0005 \\
\hline 90 & 1026 & 4 & 0.63 & 305 & 20 & 0.87 & 9027 & 0.0009 \\
\hline 120 & 795 & 3 & 0.78 & 154 & 22 & 0.86 & 9377 & 0.003 \\
\hline 180 & 835 & 4 & 0.70 & 149 & 21 & 0.88 & 7942 & 0.002 \\
\hline \multicolumn{9}{|c|}{$2 \%$ chloride } \\
\hline 1 & 449 & 5 & 0.74 & 88 & 19 & 0.89 & 11446 & 0.002 \\
\hline 7 & 347 & 7 & 0.69 & 50 & 19 & 0.88 & 9234 & 0.001 \\
\hline 15 & 277 & 7 & 0.71 & 39 & 20 & 0.86 & 21745 & 0.0007 \\
\hline 30 & 354 & 7 & 0.70 & 57 & 20 & 0.86 & 14146 & 0.001 \\
\hline 60 & 421 & 5 & 0.70 & 67 & 19 & 0.85 & 20333 & 0.006 \\
\hline 90 & 450 & 8 & 0.70 & 74 & 19 & 0.86 & 9621 & 0.005 \\
\hline 120 & 486 & 2 & 0.80 & 54 & 19 & 0.85 & 10645 & 0.002 \\
\hline 180 & 535 & 9 & 0.70 & 90 & 19 & 0.87 & 8121 & 0.001 \\
\hline \multicolumn{9}{|c|}{$5 \%$ chloride } \\
\hline 1 & 517 & 5 & 0.77 & 124 & 22 & 0.82 & 1853 & 0.001 \\
\hline 7 & 306 & 9 & 0.68 & 93 & 23 & 0.81 & 2057 & 0.008 \\
\hline 15 & 325 & 4 & 0.69 & 108 & 22 & 0.84 & 2225 & 0.003 \\
\hline 30 & 185 & 8 & 0.71 & 114 & 26 & 0.79 & 5577 & 0.003 \\
\hline 60 & 273 & 9 & 0.70 & 144 & 29 & 0.80 & 5431 & 0.005 \\
\hline 90 & 186 & 8 & 0.75 & 50 & 29 & 0.80 & 5594 & 0.0004 \\
\hline 120 & 250 & 7 & 0.69 & 68 & 28 & 0.79 & 7390 & 0.0005 \\
\hline 180 & 285 & 9 & 0.68 & 32 & 24 & 0.82 & 7668 & 0.0005 \\
\hline
\end{tabular}


TABLE 5: Parameters used in the fitting of impedance data for low-nickel SS rebar embedded in B mortar.

\begin{tabular}{|c|c|c|c|c|c|c|c|c|}
\hline Time Day & $\begin{array}{c}R_{e} \\
\Omega \mathrm{cm}^{2} \\
\end{array}$ & $\begin{array}{c}Y_{\mathrm{P}_{\mathrm{HF}}} \\
\mu \mathrm{Fcm}^{-2} \mathrm{~s}^{-\left(1-\alpha_{\mathrm{HF}}\right)}\end{array}$ & $\alpha_{\mathrm{HF}}$ & $\begin{array}{c}R_{\mathrm{HF}} \\
\Omega \mathrm{cm}^{2}\end{array}$ & $\begin{array}{c}Y_{P_{\mathrm{LF}}} \\
\mu \mathrm{Fcm}^{-2} \mathrm{~s}^{-\left(1-\alpha_{\mathrm{LF}}\right)}\end{array}$ & $\alpha_{\mathrm{LF}}$ & $\begin{array}{c}R_{\mathrm{ct}} \\
\mathrm{k} \Omega \mathrm{cm}^{2}\end{array}$ & $\chi^{2}$ \\
\hline \multicolumn{9}{|c|}{$0 \%$ chloride } \\
\hline 1 & 801 & 6 & 0.68 & 90 & 20 & 0.88 & 19090 & 0.0004 \\
\hline 7 & 711 & 4 & 0.73 & 61 & 20 & 0.90 & 17534 & 0.0005 \\
\hline 15 & 730 & 4 & 0.74 & 62 & 19 & 0.90 & 14129 & 0.0007 \\
\hline 30 & 802 & 6 & 0.72 & 82 & 19 & 0.90 & 15590 & 0.001 \\
\hline 60 & 806 & 6 & 0.72 & 73 & 19 & 0.90 & 16610 & 0.0009 \\
\hline 90 & 740 & 5 & 0.78 & 97 & 19 & 0.89 & 18110 & 0.001 \\
\hline 120 & 1219 & 2 & 0.91 & 100 & 19 & 0.89 & 19067 & 0.001 \\
\hline 180 & 727 & 9 & 0.71 & 119 & 20 & 0.88 & 22771 & 0.0006 \\
\hline \multicolumn{9}{|c|}{$2 \%$ chloride } \\
\hline 1 & 582 & 10 & 0.70 & 40 & 17 & 0.87 & 6546 & 0.002 \\
\hline 7 & 390 & 5 & 0.72 & 49 & 19 & 0.87 & 5298 & 0.001 \\
\hline 15 & 317 & 5 & 0.72 & 33 & 20 & 0.87 & 4698 & 0.002 \\
\hline 30 & 321 & 3 & 0.75 & 65 & 22 & 0.87 & 5807 & 0.009 \\
\hline 60 & 404 & 7 & 0.76 & 45 & 20 & 0.86 & 5874 & 0.006 \\
\hline 90 & 682 & 13 & 0.69 & 61 & 19 & 0.87 & 4284 & 0.003 \\
\hline 120 & 437 & 5 & 0.75 & 71 & 20 & 0.86 & 4619 & 0.003 \\
\hline 180 & 497 & 3 & 0.82 & 62 & 19 & 0.85 & 5325 & 0.005 \\
\hline \multicolumn{9}{|c|}{$5 \%$ chloride } \\
\hline 1 & 593 & 4 & 0.79 & 64 & 18 & 0.82 & 3860 & 0.003 \\
\hline 7 & 372 & 7 & 0.75 & 42 & 19 & 0.84 & 3103 & 0.0008 \\
\hline 15 & 300 & 3 & 0.82 & 25 & 22 & 0.81 & 3024 & 0.003 \\
\hline 30 & 261 & 8 & 0.75 & 25 & 20 & 0.85 & 3670 & 0.004 \\
\hline 60 & 294 & 8 & 0.74 & 32 & 21 & 0.84 & 3141 & 0.001 \\
\hline 90 & 395 & 3 & 0.75 & 55 & 18 & 0.87 & 4688 & 0.0005 \\
\hline 120 & 335 & 3 & 0.82 & 22 & 22 & 0.80 & 7468 & 0.0005 \\
\hline 180 & 341 & 5 & 0.79 & 22 & 20 & 0.84 & 6322 & 0.0004 \\
\hline
\end{tabular}

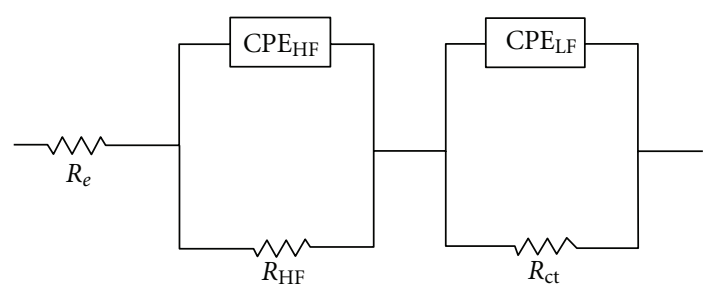

Figure 5: Equivalent electrical circuit (EEC) used to fit impedance data for low-nickel SS rebar embedded in mortars A and B with different chloride additions.

relaxation time constants (see Figure 4). The $\mathrm{CPE}_{\mathrm{HF}}-R_{\mathrm{HF}}$ couple, which predominated at high frequencies, may be originated by the characteristics of a corrosion product layer, adherent to the reinforcing bars, while the $\mathrm{CPE}_{\mathrm{LF}}-R_{\mathrm{ct}}$ couple, controlling at low frequencies, characterises the corrosion process of double layer on the steel electrode. $R_{e}$ was again the electrolyte resistance [22].
Table 4 includes optimised fitting impedance parameter values for the $\mathrm{A} /$ steel system. The $R_{e}$ values for lownickel stainless steel were in the range from $795 \Omega \mathrm{cm}^{2}$ to $2442 \Omega \mathrm{cm}^{2}$ for mortars without chloride, while they were lower, $535 \Omega \mathrm{cm}^{2}$ and $517 \Omega \mathrm{cm}^{2}$ in the cases of mortar with $2 \%$ and $5 \%$ chlorides, respectively. This decrease in the $\mathrm{R}_{e}$ parameter may be attributed to a high concentration of free chloride ions in the pore network of the mortar, which enhance the electrical conductivity. At high frequency, a semicircle can be seen (Figure 4(a)) which may be associated with the characteristics of a corrosion product layer. The high-frequency process had a $\mathrm{CPE}_{\mathrm{HF}}\left(Y_{P_{\mathrm{HF}}}\right)$ in the range from $2 \mu \mathrm{Fcm}^{-2} \mathrm{~s}^{-\left(1-\alpha_{\mathrm{HF}}\right)}$ to $9 \mu \mathrm{Fcm}^{-2} \mathrm{~s}^{-\left(1-\alpha_{\mathrm{HF}}\right)}$, passive layer resistance $\left(R_{\mathrm{HF}}\right)$ values from $149 \Omega \mathrm{cm}^{2}$ to $422 \Omega \mathrm{cm}^{2}$ were found in the absence of chlorides and from $32 \Omega \mathrm{cm}^{2}$ to $144 \Omega \mathrm{cm}^{2}$ for mortar with $5 \%$ chlorides. Thus, the addition of a high chloride percentage originated a decrease in the $R_{\mathrm{HF}}$ parameter, suggesting that the passive film was less protective and its thickness was lower. Therefore, the mortar A containing $5 \%$ chlorides presented low corrosion resistance. Finally, at low frequencies a capacitive behaviour was observed, and 
the charge transfer resistance $\left(R_{\mathrm{ct}}\right)$, obtained from numerical fitting (see Table 4), was as high as $7668 \mathrm{k} \Omega \mathrm{cm}^{2}$, indicating the permanence of the passive state.

Table 5 includes optimised fitting impedance parameter values for the $\mathrm{B} /$ steel system. The high frequency process had a $\operatorname{CPE}_{\mathrm{HF}}\left(Y_{P_{\mathrm{HF}}}\right)$ in the range from $2 \mu \mathrm{Fcm}^{-2} \mathrm{~s}^{-\left(1-\alpha_{\mathrm{HF}}\right)}$ to $13 \mu \mathrm{Fcm}^{-2} \mathrm{~s}^{-\left(1-\alpha_{\mathrm{HF}}\right)}$. The $Y_{\mathrm{HF}}$ and $\alpha_{\mathrm{HF}}$ parameters were similar to those obtained for steel embedded in A mortars, suggesting that the surface film was equal protective and the mortar presented low corrosion rate. The $R_{e}$ and $R_{\mathrm{HF}}$ values for low-nickel stainless steel were in the range from $261 \Omega \mathrm{cm}^{2}$ to $1219 \Omega \mathrm{cm}^{2}$ and from $22 \Omega \mathrm{cm}^{2}$ to $119 \Omega \mathrm{cm}^{2}$, respectively.

A depressed capacitive semicircle was also observed at low frequency (see Table 5), $Y_{P_{\mathrm{LF}}}$ values were in the range of $17-22 \mu \mathrm{Fcm}^{-2} \mathrm{~s}^{-\left(1-\alpha_{\mathrm{LF}}\right)}$. These values may indicate the no gradual breakdown of the passive film. At increasing times, $\alpha_{\mathrm{LF}}$ values were constant, showing that the steel surface became homogeneous. Finally, the $R_{\mathrm{ct}}$ values were extrapolated by fitting the low frequency portion of the diagram by a semicircle. This value was as high as $7468 \mathrm{k} \Omega \mathrm{cm}^{2}$ in the presence of $5 \%$ chlorides.

Therefore, it can be observed that the $R_{\mathrm{ct}}$ of the lownickel SS embedded in both fly ash mortars with 5\% chlorides additions were also very high. Accepting that the SternGeary equation can be applied, with an approximate B constant value of $52 \mathrm{mV}$ [29], the resulting $i_{\text {corr }}$ was 0.0068 $\mu \mathrm{A} \mathrm{cm}^{-2}$ and $0.0070 \mu \mathrm{A} \mathrm{cm}{ }^{-2}$ for $\mathrm{A}$ and $\mathrm{B}$ mortars, respectively. This suggests the very low corrosion susceptibility of the low-nickel SS reinforcements in these mortars in a very aggressive medium ( $5 \%$ chlorides).

Low-nickel SS presented $R_{\mathrm{ct}}$ values of $212280 \Omega \mathrm{cm}^{2}$ in the presence of $5 \% \mathrm{Cl}^{-}$, applying the Stern-Geary equation, the $i_{\text {corr }}$ was $0.26 \mu \mathrm{A} \mathrm{cm}^{-2}$. The results achieved in synthetic solution suggest low-nickel SS exhibit high corrosion resistance. Therefore, the effect caused by the reduced Ni content is almost balance by the beneficial effect of other additives such as manganese or nitrogen. In the present study and in the literature $[14,15]$, the influence of the metal base composition on the corrosion process has proved not to be a very important factor, and the low-nickel SS in synthetic solution with chloride has a good durability.

According to the $i_{\text {corr }}$ obtained for mortars A and B, suggesting that these fly ash cements due to their high alkalinity should limit rebar corrosion to negligible levels. Moreover, the microstructure of these mortars is dense and compact, leading to a system with a lower porosity [28], which causes difficulty in the mobility of chloride ions to the steel surface. The use of low-nickel SS embedded in fly ash mortars guarantee the durability of reinforced concrete structures in aggressive environment. However, in a previous work, Boqi et al. [30] have demonstrated that the corrosion of reinforcements in coastal harbour were most severe in the high tide level zone, while no damage was found in the tide range and underwater positions. Therefore, it is suggested that the presence of chlorides may or not damage the reinforced cement structures, but the location of structures must be taken into account so that it is an important factor. In light of these last results and knowing that the tests of the present study were carried out at early age (180 days of experimentation), further investigations are necessary to asses if the low-nickel SS embedded in fly ash mortars are a viable material to be used in real structures that need to last 50-100 years.

\section{Conclusions}

EIS results obtained for low-nickel SS in alkaline-saturated calcium hydroxide solution showed that $R_{\mathrm{ct}}$ values decreased with the addition of $\mathrm{NaCl}$. Nevertheless, $R_{\mathrm{ct}}$ values were so high that low-nickel SS preserved its passivity, exhibiting high corrosion resistance. Diffusion processes were observed for low-nickel SS. The $\sigma_{w}$ values obtained showed that for a $\mathrm{NaCl}$ concentration higher than or equal to $3.0 \%$ a less compact and protective passive film was formed.

EIS results obtained for low-nickel SS in fly ash mortars showed that $i_{\text {corr }}$ values were of the order of $0.007 \mu \mathrm{A} / \mathrm{cm}^{2}$ in the presence of chlorides independently of the type of activator used. These results suggest a good durability of lownickel SS in these mortars with $5 \%$ chlorides at 180 days of experimentation.

\section{Acknowledgments}

M. Criado and S. Fajardo express their gratitude to the Spanish Research Council (CSIC) for their Contract under the Juan de la Cierva and the JAE Program, respectively, cofinanced by the European. The authors express their gratitude to Project BIA2008-05398 from CICYT, Spain, for financial support and to ACERINOX SA for supplying the tested low-nickel stainless steels.

\section{References}

[1] L. Bertolini, B. Elsener, P. Pedeferri, and R. Polder, Corrosion of Steel in Concrete: Prevention, Diagnosis, Repair, Wiley VCH, New York, NY, USA, 2004.

[2] M. A. G. Tommaselli, N. A. Mariano, and S. E. Kuri, "Effectiveness of corrosion inhibitors in saturated calcium hydroxide solutions acidified by acid rain components," Construction and Building Materials, vol. 23, no. 1, pp. 328-333, 2009.

[3] J. M. Miranda, A. Fernández-Jiménez, J. A. González, and A. Palomo, "Corrosion resistance in activated fly ash mortars," Cement and Concrete Research, vol. 35, no. 6, pp. 1210-1217, 2005.

[4] D. M. Bastidas, A. Fernández-Jiménez, A. Palomo, and J. A. González, "A study on the passive state stability of steel embedded in activated fly ash mortars," Corrosion Science, vol. 50, no. 4, pp. 1058-1065, 2008.

[5] R. Montoya, W. Aperador, and D. M. Bastidas, "Influence of conductivity on cathodic protection of reinforced alkali-activated slag mortar using the finite element method," Corrosion Science, vol. 51, no. 12, pp. 2857-2862, 2009.

[6] M. B. Valcarce and M. Vázquez, "Carbon steel passivity examined in alkaline solutions: the effect of chloride and nitrite ions," Electrochimica Acta, vol. 53, no. 15, pp. 5007-5015, 2008.

[7] N. R. Baddoo, "Stainless steel in construction: a review of research, applications, challenges and opportunities," Journal of Constructional Steel Research, vol. 64, no. 11, pp. 1199-1206, 2008.

[8] A. Bautista, G. Blanco, F. Velasco, and M. A. Martínez, "Corrosion performance of welded stainless steels reinforcements 
in simulated pore solutions," Construction and Building Materials, vol. 21, no. 6, pp. 1267-1276, 2007.

[9] R. Merello, F. J. Botana, J. Botella, M. V. Matres, and M. Marcos, "Influence of chemical composition on the pitting corrosion resistance of non-standard low-ni high-mn-n du-plex stainless steels," Corrosion Science, vol. 45, no. 5, pp. 909-921, 2003.

[10] L. Freire, X. R. Nóvoa, G. Pena, and V. Vivier, "On the corrosion mechanism of aisi $204 \mathrm{cu}$ stainless steel in chlorinated alkaline media," Corrosion Science, vol. 50, no. 11, pp. 32053212, 2008.

[11] D. Trejo and P. J. Monteiro, "Corrosion performance of conventional (ASTM a615) and low-alloy (ASTM A706) reinforcing bars embedded in concrete and exposed to chloride environments," Cement and Concrete Research, vol. 35, no. 3, pp. 562-571, 2005.

[12] L. Veleva, M. A. Alpuche-Aviles, M. K. Graves-Brook, and D. O. Wipf, "Comparative cyclic voltammetry and surface analysis of passive films grown on stainless steel 316 in concrete pore model solutions," Journal of Electroanalytical Chemistry, vol. 537, no. 1-2, pp. 85-93, 2002.

[13] G. S. Frankel, "Pitting corrosion of metals: a review of the critical factors," Journal of the Electrochemical Society, vol. 145, no. 6, pp. 2186-2198, 1998.

[14] M. C. García-Alonso, M. L. Escudero, J. M. Miranda et al., "Corrosion behaviour of new stainless steels reinforcing bars embedded in concrete," Cement and Concrete Research, vol. 37, no. 10, pp. 1463-1471, 2007.

[15] M. C. García-Alonso, J. A. González, J. Miranda et al., "Corrosion behaviour of innovative stainless steels in mortar," Cement and Concrete Research, vol. 37, no. 11, pp. 1562-1569, 2007.

[16] A. Bautista, G. Blanco, and F. Velasco, "Corrosion behaviour of low-nickel austenitic stainless steels reinforcements: a comparative study in simulated pore solutions," Cement and Concrete Research, vol. 36, no. 10, pp. 1922-1930, 2006.

[17] J. A. Gonzalez, S. Feliu, P. Rodriguez, E. Ramirez, C. Alonso, and C. Andrade, "Some questions on the corrosion of steel in concrete. Part I: when, how and how much steel corrodes," Materials and Structures, vol. 29, pp. 40-46, 2006.

[18] T. Smith, "New electrochemical cell for pitting corrosion testing," Corrosion Science, vol. 29, pp. 135-140, 1988.

[19] "Stainless steel. Part 1: list of stainless steel," UNE-EN 100881:2006.

[20] "Standard specification for chromium and chromium-nickel stainless steel plate, sheet, and strip for pressure vessels and for general applications.," ASTM A240/A240M-11b.

[21] O. Poupard, A. Ait-Mokhtar, and P. Dumargue, "Impedance spectroscopy in reinforced concrete: procedure for monitoring steel corrosion: part I development of the experimental device," Journal of Materials Science, vol. 38, no. 13, pp. 28452850, 2003.

[22] V. Feliu, J. A. González, C. Andrade, and S. Feliu, "Equivalent circuit for modelling the steel-concrete interface. I. experimental evidence and theoretical predictions," Corrosion Science, vol. 40, no. 6, pp. 975-993, 1998.

[23] T. Hong, G. W. Walter, and M. Nagumo, "The observation of the early stages of pitting on passivated type 304 stainless steel in a $0.5 \mathrm{M} \mathrm{NaCl}$ solution at low potentials in the passive region by using the AC impedance method," Corrosion Science, vol. 38, no. 9, pp. 1525-1533, 1996.

[24] W. Chen, R.-G. Du, C.-Q. Ye, Y.-F. Zhu, and C.-J. Lin, "Study on the corrosion behavior of reinforcing steel in simulated concrete pore solutions using in situ Raman spectroscopy assisted by electrochemical techniques," Electrochimica Acta, vol. 55, no. 20, pp. 5677-5682, 2010.

[25] U. Rammelt and G. Reinhard, "On the applicability of a constant phase element (CPE) to the estimation of roughness of solid metal electrodes," Electrochimica Acta, vol. 35, no. 6, pp. 1045-1049, 1990.

[26] M. Leibig and T. C. Halsey, "The double layer impedance as a probe of surface roughness," Electrochimica Acta, vol. 38, no. 14, pp. 1985-1988, 1993.

[27] S. Fajardo, D. M. Bastidas, M. Criado, M. Romero, and J. M. Bastidas, "Corrosion behaviour of a new low-nickel stainless steel in saturated calcium hydroxide solution," Construction and Building Materials, vol. 25, no. 11, pp. 4190-4196, 2011.

[28] M. Criado, D. M. Bastidas, S. Fajardo, A. Fernández-Jiménez, and J. M. Bastidas, "Corrosion behaviour of a new low-nickel stainless steel embedded in activated fly ash mortars," Cement and Concrete Composites, vol. 33, no. 6, pp. 644-652, 2011.

[29] C. Andrade, V. Castelo, C. Alonso, and J. A. Gonzalez, "The determination of the corrosion rate of steel embedded in concrete by the polarization resistance and AC impedance methods," in Proceedings of the STP 906, Corrosion of Rebar in Concrete, ASTM, Philadelphia, Pa, usa, 1984.

[30] C. Boqi, H. Dinghai, G. Hengquan, and Z. Yinghao, "Ten-year field exposure tests on the endurance of reinforced concrete in harbor works," Cement and Concrete Research, vol. 13, no. 5, pp. 603-610, 1983. 

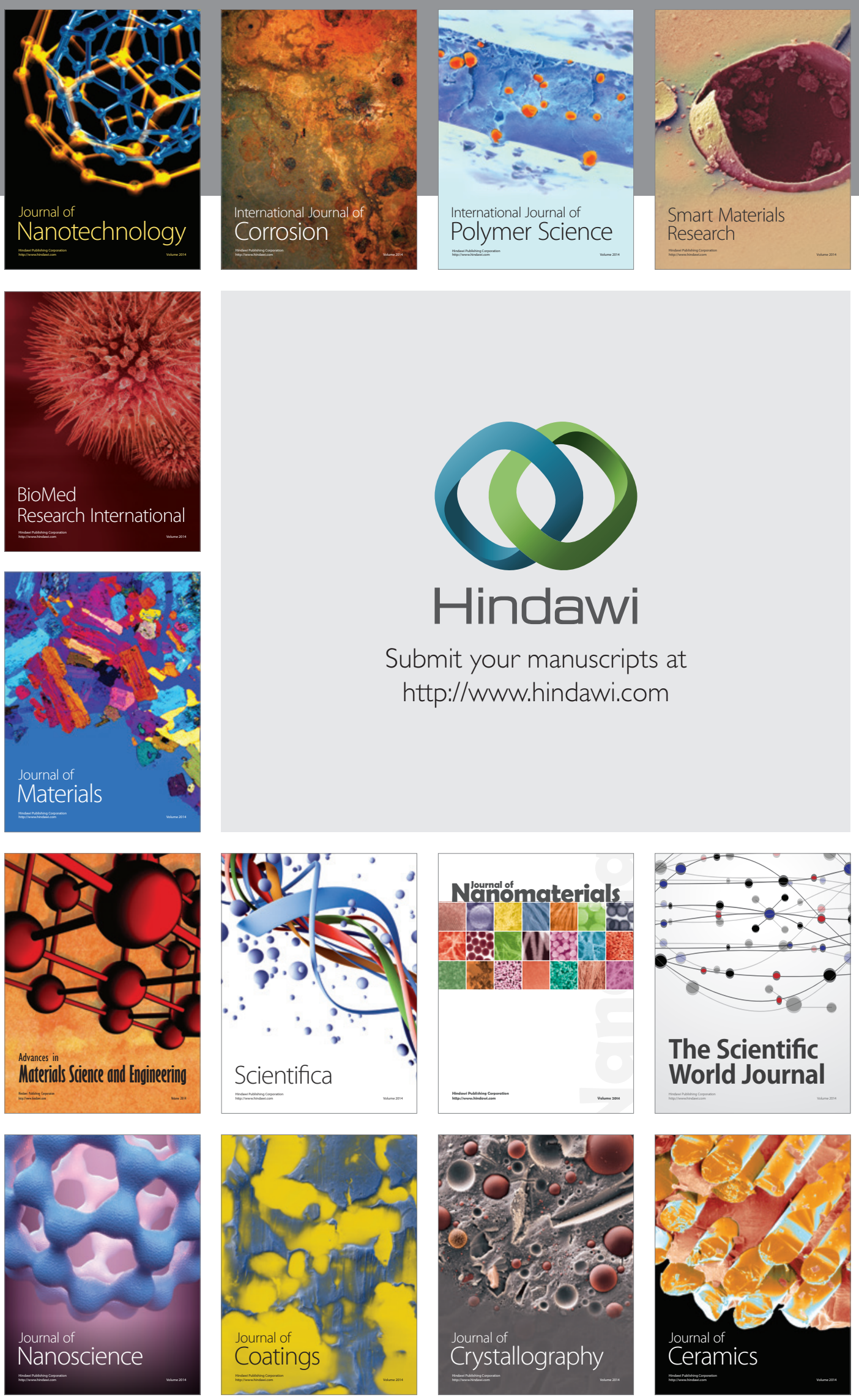

The Scientific World Journal

Submit your manuscripts at

http://www.hindawi.com

\section{World Journal}

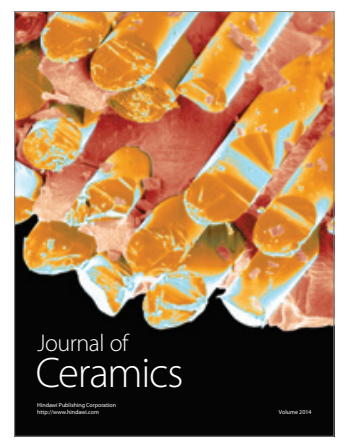

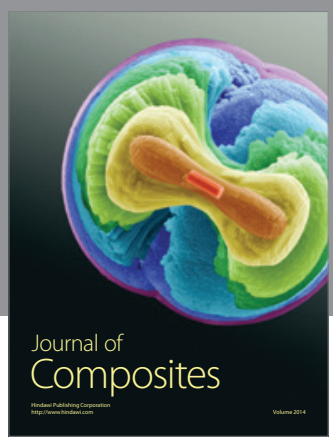
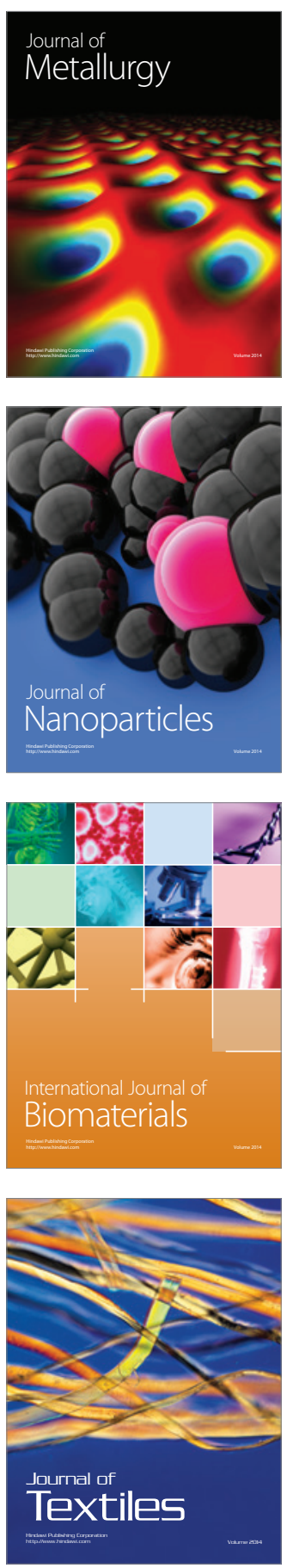